\title{
Tuttnauer
}

\section{State-of-the-art equipment for sterilization and biocontainment since 1925}

\author{
David Morganstern \& Jake Miller
}

\begin{abstract}
Tuttnauer is a worldwide leader in the market for sterilization and infection control. An expansive global presence has aided Tuttnauer's growth over the past four decades. Tuttnauer's products are marketed through seven subsidiaries with local dealers in over 120 countries. The company also holds offices in the United States, Netherlands, India, China, and Vietnam. Facing the most challenging and complex projects worldwide, Tuttnauer has become a driving force in advancing technology in this market to a new standard.
\end{abstract}

In 1987, Tuttnauer started exporting to the USA and since then it has become the authority for autoclaves in the markets of physicians and laboratories. Prestigious research institutions, medical schools, universities, hospitals and animal care facilities all trust Tuttnauer to answer their needs for sterilization and infection control.

\section{One area of expertise-unlimited applications}

Tuttnauer entered the market for sterilization and infection control in 1925, when it first provided autoclaves for the British army. Ever since, Tuttnauer has developed new technologies and a full range of sterilization, cleaning and disinfection solutions for a variety of markets and applications. Its products include high-end gravity autoclaves and pre- and post-vacuum tabletop autoclaves that are suitable for private practices and clinics, with chamber sizes ranging between 7.5 and 160 liters. The larger, horizontal line of products includes autoclaves with chamber volumes of 120-17,000 liters, which provide sterilization and disinfection solutions for hospitals, medical facilities, pharmaceutical manufacturing and laboratories (Fig. 1). A user-friendly, color touch screen interface, stainless steel piping and air-operated valves make Tuttnauer horizontal autoclaves a preferred choice.

\section{Focus on the animal care market}

Tuttnauer's focus on the market for animal care has brought the company together with leading research institutions. Its autoclave line can be tailored to meet the specific requirements of laboratories classified as Animal Biosafety Level 3 or 4 . Tuttnauer offers biocontainment packages that include seals to prevent cross-contamination, mechanisms to sterilize effluent and a host of other options designed for optimal isolation. Tuttnauer also offers two different types of effluent decontamination systems that prevent the release of microorganisms into the environment. Both systems effectively sterilize the aerosol inside the air stream that is removed at the start of the sterilization cycle. The first method uses a jacketed, steam-heated filter whereas the second relies on a steam ejector venturi, with an exclusive, unique design that requires no maintenance.

Tuttnauer USA, Hauppauge, NY. Correspondence should be addressed to D.M. (davidm@tuttnauerusa.com).

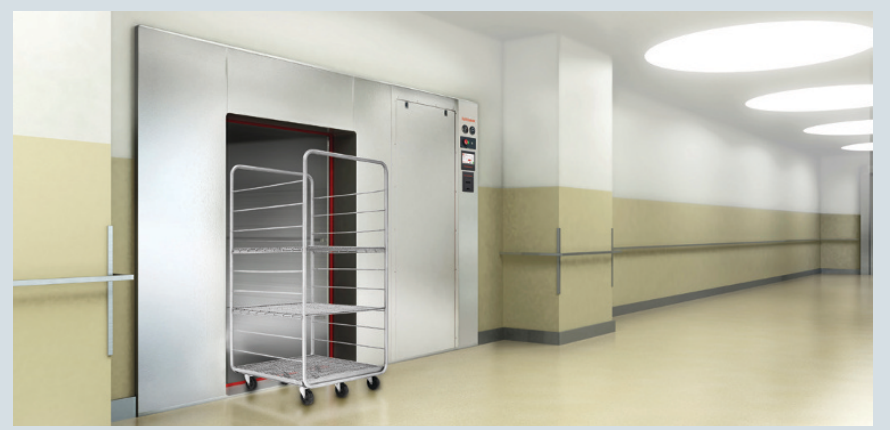

FIGURE 1 | Tuttnauer bulk sterilizer and floor loading cart

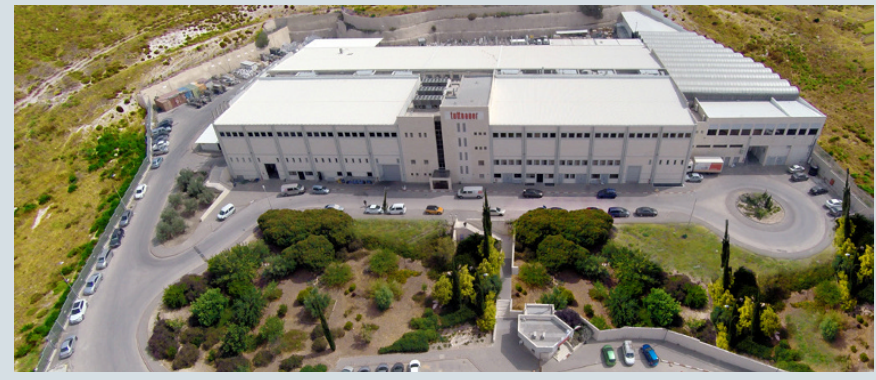

FIGURE 2 | Tuttnauer's state-of-the-art factory

\section{State-of-the-art manufacturing facility}

Tuttnauer's manufacturing plant is over 325,000 square feet (Fig. 2) and is considered the largest autoclave production facility in the world. Fully automated, their factory applies advanced machinery and robotics, engineering techniques and eco-friendly technologies, which keeps the company at the forefront of the market for infection control. Accurate cutting with lasers minimizes the number of welds used in construction, and Tuttnauer's use of the highest available grade of material yields quality products that are trusted worldwide. Tuttnauer also produces custom sizes and configurations.

This article was submitted to Lab Animal by a commercial organization and has not been peer-reviewed. Lab Animal takes no responsibility for the accuracy or relevancy of the information provided therein. 